\title{
Investigation of pressure-induced magnetic transitions in $\mathrm{Co}_{x} \mathrm{Fe}_{3-x} \mathrm{O}_{4}$ spinels
}

\author{
G. Subías, ${ }^{1, *}$ V. Cuartero, ${ }^{2}$ J. García, ${ }^{1}$ J. Blasco, ${ }^{1}$ S. Lafuerza, ${ }^{1}$ S. Pascarelli, ${ }^{3}$ O. Mathon, ${ }^{3}$ C. Strohm, ${ }^{3}$ \\ K. Nagai ${ }^{4}$ M. Mito, ${ }^{4}$ and G. Garbarino ${ }^{3}$ \\ ${ }^{1}$ ICMA-Instituto de Ciencia de Materiales de Aragón, Departamento de Física de la Materia Condensada, \\ Universidad de Zaragoza-CSIC, 50009-Zaragoza, Spain \\ ${ }^{2}$ ALBA Synchrotron/CELLS, Cerdanyola del Vallès, 08290, Spain \\ ${ }^{3}$ European Synchrotron Radiation Facility, BP 220, 38043 Grenoble Cedex, France \\ ${ }^{4}$ Faculty of Engineering, Kyushu Institute of Technology, Kitakyushu, Fukuoka 804-8550, Japan
}

(Received 4 November 2012; published 7 March 2013)

\begin{abstract}
Room temperature $\mathrm{Fe}$ and $\mathrm{Co}$ K-edge x-ray magnetic circular dichroism, synchrotron $\mathrm{x}$-ray powder diffraction, and magnetization measurements were carried out to investigate the stability of the ferrimagnetic ground state in $\mathrm{Co}_{x} \mathrm{Fe}_{3-x} \mathrm{O}_{4}(x=0,1,1.5$, and 2$)$ ferrites under pressure up to about $30 \mathrm{GPa}$ using diamond anvil cells. The $\mathrm{x}$-ray magnetic circular dichroism at the $\mathrm{Fe} \mathrm{K}$-edge is observed to decrease continuously up to the highest reached pressure by $\sim 50 \%$ in $\mathrm{Fe}_{3} \mathrm{O}_{4}$ (at $25 \mathrm{GPa}$ ) and by $\sim 70 \%$ in $\mathrm{Co}_{1.5} \mathrm{Fe}_{1.5} \mathrm{O}_{4}$ (at $16 \mathrm{GPa}$ ) and $\mathrm{Co}_{2} \mathrm{FeO}_{4}$ (at $21 \mathrm{GPa}$ ). In $\mathrm{CoFe}_{2} \mathrm{O}_{4}$, the suppression by $\sim 80 \%$ of the $\mathrm{x}$-ray magnetic circular dichroic signal occurs simultaneously at both $\mathrm{Fe}$ and $\mathrm{Co} \mathrm{K}$-edges between 24 and $27 \mathrm{GPa}$. However, a continuous decrease of the dichroic signal with pressure is only observed at the Co K-edge, whereas the Fe K-edge dichroic intensity drops drastically. The synchrotron $\mathrm{x}$-ray powder diffraction measurements indicate the occurrence of structural phase transitions at critical pressures in coincidence with the suppression of ferrimagnetism. In $\mathrm{CoFe}_{2} \mathrm{O}_{4}$, bulk magnetization measurements up to 26 GPa confirm the disappearance of ferrimagnetism and indicate an almost linear dependence of the magnetization with the magnetic field in the high pressure phase. We thus conclude that high-pressure $\mathrm{CoFe}_{2} \mathrm{O}_{4}$ is either paramagnetic or antiferromagnetic.
\end{abstract}

DOI: 10.1103/PhysRevB.87.094408

PACS number(s): 62.50.-p, 75.47.Lx

\section{INTRODUCTION}

In magnetic materials with strong electron correlations such as transition-metal oxides, lattice compression strongly affects transport, structural, and magnetic properties, often leading to a high-pressure-induced insulator-to-metal transition accompanied by the loss of its ferromagnetic long-range order and by a structural phase transition. Such transformations have been experimentally observed in various transition metal compounds, ${ }^{1}$ but the mechanisms of these transitions are still ambiguous in many respects especially in the relation to the local, atomic scale electronic and magnetic modifications at the high-pressure phase.

Spinel ferrites with $\mathrm{AB}_{2} \mathrm{O}_{4}$ formula are transition-metal ternary oxides that have a wide range of applications because of their ferrimagnetic and electrical properties ${ }^{2}$ that are governed by the choice of the cations along with $\mathrm{Fe}^{3+}-\mathrm{Fe}^{2+}$ ions and their distribution between the tetrahedral $\mathrm{A}$ and octahedral B sites. Particularly, magnetite is, at ambient conditions, a ferrimagnetic cubic inverse spinel where the tetrahedral A and octahedral $\mathrm{B}$ sites are occupied by nominally $\mathrm{Fe}^{3+}$ and mixedvalent $\mathrm{Fe}^{2.5+}$ configurations, respectively. ${ }^{3}$ Its high-pressure behavior has been extensively studied by $\mathrm{x}$-ray diffraction (XRD),${ }^{4-7}$ Mössbauer spectroscopy, ${ }^{8,9}$ and electrical resistivity measurements. ${ }^{9,10}$ Above $25 \mathrm{GPa}$, magnetite undergoes a sluggish structural transformation to a high-pressure phase $e^{4-7}$ as reflections of the low-pressure spinel phase could be traced up to at least $60 \mathrm{GPa}$. Powder XRD experiments of this high-pressure structure were indexed in the orthorhombic unit cell $\left(\mathrm{CaMn}_{2} \mathrm{O}_{4}\right.$-type structure, space group $\left.\mathrm{Pbcm}\right)$ by Fei et al. (Ref. 5) but also in a more symmetric $\mathrm{CaTi}_{2} \mathrm{O}_{4}$-type structure (space group Bbmm), as proposed by Haavick et al. (Ref. 6) and recently confirmed by Dubrovinsky et al. (Ref. 7). This high-pressure structure does not order magnetically at $300 \mathrm{~K}^{7}$ and shows a semiconductorlike behavior. ${ }^{9,10} \mathrm{Fe}$ K-edge x-ray magnetic circular dichroism (XMCD) measurements ${ }^{11-13}$ have been reported to give a comprehensive view of the magnetic behavior of magnetite with pressure. A pressure-induced magnetic transition shown by a sharp decrease $(\sim 50 \%)$ in the amplitude of the XMCD signal was reported between 12 and $16 \mathrm{GPa}$ by Ding et al. (Ref. 11). This abrupt change was interpreted as a high-spin to intermediate-spin transition of $\mathrm{Fe}^{2+}$ ions in octahedral sites. However, two more recent XMCD experiments ${ }^{12,13}$ challenge this abrupt high-spin to intermediate-spin transition. They observed a monotonous decrease of the magnetic moment with pressure of about $50 \%$ from ambient to $25 \mathrm{GPa}$ in Ref. 12 and of about $60 \%$ from ambient to $41 \mathrm{GPa}$ in Ref. 13, respectively. These works agree with the sluggish nature of the phase transformation because Pasternak et al. ${ }^{8}$ estimated that only about $60 \%$ of magnetite transforms into the high-pressure polymorph on compression to $66 \mathrm{GPa}$ at ambient temperature, and thus, the ferrimagnetic order is still not lost. Moreover, it reverts to the original magnetite phase by decompression following a hysteresis. ${ }^{8}$ Furthermore, Baudelet et al. ${ }^{13}$ plaid for a band-structure description, where the total loss of the ferrimagnetism is associated with the onset of full metallic behavior.

The purpose of the present study is to give tracks on the mechanism for the pressure-induced magnetic transition reported in magnetite. The loss of ferromagnetism with pressure can be accounted for either by the formation of a zero net moment magnetic phase (paramagnetic or antiferromagnetic) or by the so-called magnetic collapse into a nonmagnetic metallic state. The former case is related 
to shifts of the magnetic-order temperature with pressure, whereas the latter transition is due to the $3 \mathrm{~d}$ band widening with increasing pressure, which decreases the density of states at the Fermi level below the stability limit for ferromagnetism given by the Stoner criterion. ${ }^{14}$ The delocalization of the $3 \mathrm{~d}$ electrons results in metallization concurrently with the loss of the local magnetic moments. Low-temperature high-pressure XMCD measurements might resolve between these two points. However, the experiment may not be trivial.

Therefore, we have studied the stability of ferrimagnetism in the related cobalt-iron oxides $\mathrm{Co}_{x} \mathrm{Fe}_{3-x} \mathrm{O}_{4}(x=1,1.5$, and 2 ) in comparison with magnetite. In particular, $\mathrm{CoFe}_{2} \mathrm{O}_{4}$ has the same inverse-spinel structure as magnetite, with divalent Co ions occupying predominantly the octahedral sites, ${ }^{15}$ and $T_{N} \sim 790 \mathrm{~K}$, only a bit lower than that of magnetite $(\sim 850 \mathrm{~K})$. The degree of cation disordering over the tetrahedral and octahedral sites can be described using an inversion parameter (i) and the formula $\left(\mathrm{M}^{3+}{ }_{i} \mathrm{M}^{2+}{ }_{1-i}\right)_{\mathrm{A}}\left(\mathrm{M}^{2+}{ }_{i} \mathrm{M}^{3+}{ }_{2-i}\right)_{\mathrm{B}} \mathrm{O}_{4}$, where $i=0$ for a normal (ordered) spinel and $i=1$ for an inverse (antiordered) spinel. Figure 1 shows the site occupancy of $\mathrm{Fe}$ and $\mathrm{Co}$ atoms for the cobalt-iron ferrites derived from their Fe K-edge XMCD spectra ${ }^{16}$ and takes into account that the addition of $\mathrm{Co}$ to $\mathrm{CoFe}_{2} \mathrm{O}_{4}$ ( $i=1$ antiordered) makes the cation distribution more normal so that $\mathrm{Co}^{3+}$ enters into octahedral $\mathrm{B}$ sites and $\mathrm{Co}^{2+}$ moves from B sites to A sites. ${ }^{17}$ This results in two intermediate cases of partially inverse

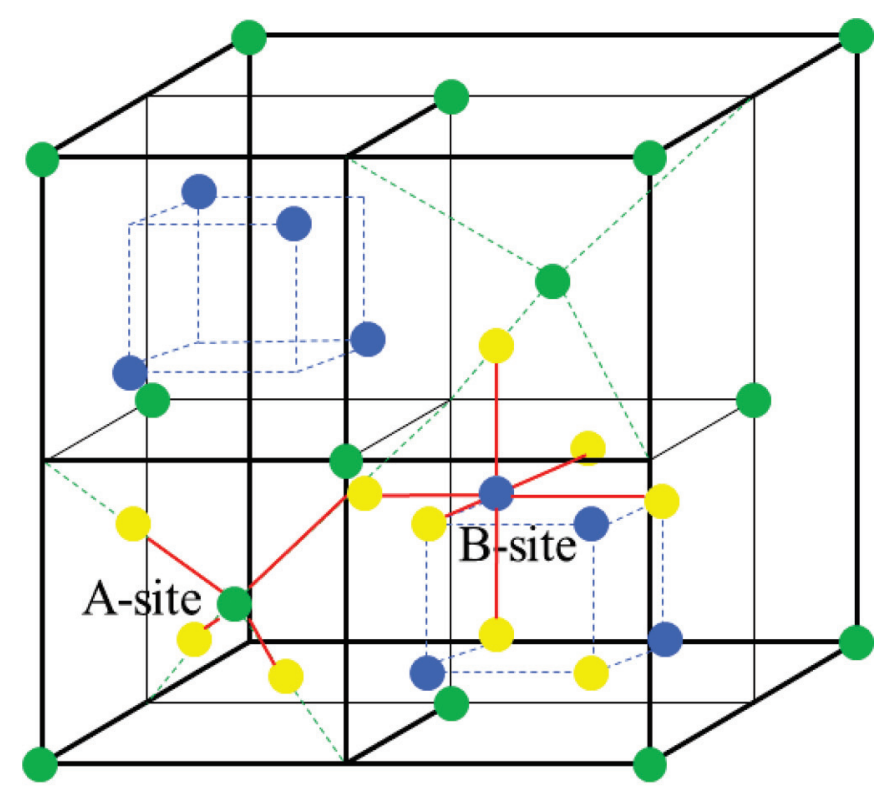

\begin{tabular}{c|c|c} 
Sample & A-site & B-site \\
\hline $\mathrm{CoFe}_{2} \mathrm{O}_{4}{ }^{\mathrm{a}}$ & $\mathrm{Fe}^{3+}$ & $\mathrm{Fe}^{3+} \mathrm{Co}^{2+}$ \\
\hline $\mathrm{Co}_{1.5} \mathrm{Fe}_{1.5} \mathrm{O}_{4}{ }^{\mathrm{b}}$ & $\mathrm{Fe}^{3+}{ }_{0.7} \mathrm{Co}^{2+}{ }_{0.3}$ & $\mathrm{Fe}^{3+}{ }_{0.8} \mathrm{Co}^{2+}{ }_{0.7} \mathrm{Co}^{3+}{ }_{0.5}$ \\
\hline $\mathrm{Co}_{2} \mathrm{FeO}_{4}{ }^{\mathrm{b}}$ & $\mathrm{Fe}^{3+}{ }_{0.4} \mathrm{Co}^{2+}{ }_{0.6}$ & $\mathrm{Fe}^{3+}{ }_{0.6} \mathrm{Co}^{2+}{ }_{0.4} \mathrm{Co}^{3+}$ \\
\hline
\end{tabular}

${ }^{2}$ Reference 15

'Reference 16

FIG. 1. (Color online) Spinel structure of $\mathrm{Co}_{x} \mathrm{Fe}_{3-x} \mathrm{O}_{4}(x=1$, 1.5, and 2) ferrites showing the location of constituents, namely $\mathrm{Fe}^{3+}$ and $\mathrm{Co}^{n+} / \mathrm{Fe}^{3+}$ at the tetrahedral $\mathrm{A}$ (green balls) and octahedral $\mathrm{B}$ (blue balls) sites. Oxygen atoms are represented by yellow balls. spinels: the almost fully disordered $\mathrm{Co}_{1.5} \mathrm{Fe}_{1.5} \mathrm{O}_{4}$ with $i=0.7$ and the partially ordered $\mathrm{CoFe}_{2} \mathrm{O}_{4}$ with $i=0.4$.

In this paper, we report combined room temperature XMCD measurements at the $\mathrm{Fe}$ and $\mathrm{Co} \mathrm{K}$-edges, magnetization, and synchrotron XRD studies up to $\sim 30 \mathrm{GPa}$. We find that all the samples show diminished ferrimagnetism with pressure, the pressure-induced magnetic suppression taking place in the same range of pressures as the structural phase transitions. Based on our experiments measuring for the first time the magnetic field $(H)$ dependence of bulk magnetization under high pressure, in the particular case of $\mathrm{CoFe}_{2} \mathrm{O}_{4}$, we discard unambiguously the magnetic collapse as the principal mechanism for ferrimagnetism suppression in this inverse spinel ferrite. In fact, it is found that high-pressure $\mathrm{CoFe}_{2} \mathrm{O}_{4}$ is either a paramagnet or an antiferromagnet.

\section{EXPERIMENTAL}

Polycrystalline samples of $\mathrm{CoFe}_{2} \mathrm{O}_{4}, \mathrm{Co}_{1.5} \mathrm{Fe}_{1.5} \mathrm{O}_{4}$, and $\mathrm{Co}_{2} \mathrm{FeO}_{4}$ were synthesized from solid state methods. Stoichiometric amounts of $\mathrm{Co}_{3} \mathrm{O}_{4}$ and $\mathrm{Fe}_{2} \mathrm{O}_{3}$ were first mixed and fired at $900{ }^{\circ} \mathrm{C}$ overnight. The obtained powders were ground again and pressed into pellets. The sintering process was adapted to the chemical composition of the sample. $\mathrm{CoFe}_{2} \mathrm{O}_{4}$ was then sintered at $1100^{\circ} \mathrm{C}$ for $48 \mathrm{~h}$ in air and cooled down to room temperature. $\mathrm{Co}_{1.5} \mathrm{Fe}_{1.5} \mathrm{O}_{4}$ and $\mathrm{Co}_{2} \mathrm{FeO}_{4}$ were sintered at $1100{ }^{\circ} \mathrm{C}$ in the same conditions, but they were slowly cooled $\left(1^{\circ} \mathrm{C} / \mathrm{min}\right)$ down to $925^{\circ} \mathrm{C}$ and quenched into air to prevent a decomposition into two spinel phases. ${ }^{18}$ The samples were characterized by $\mathrm{x}$-ray powder diffraction and magnetic measurements ensuring the correct oxygen stoichiometry. All samples were single phase (cubic spinel) at room temperature. Powdered crystals of magnetite were obtained from crushing a piece of a high-quality single-crystal grown by the floating zone method. ${ }^{19}$

High-pressure room temperature XANES and XMCD measurements were carried out on the energy dispersive ID24 beam line ${ }^{20}$ at the European Synchrotron Radiation Facility (ESRF) in Grenoble, France. The powder samples, mixed with silicone oil as a pressure-transmitting medium, were loaded into a nonmagnetic $\mathrm{CuBe}$ diamond anvil cell (DAC) equipped with a pair of 1.2-mm-thick diamond anvils. Ruby chips were used as pressure markers, and the magnetic field was $\sim 7 \mathrm{kOe}$. Circular polarization was attained using a diamond quarter wave plate. Two sets of measurements at each pressure with both polarization helicities and both magnetic field directions were taken in order to eliminate systematic errors arising from the positioning of the quarter wave plate for the two helicities and changing the direction of the magnetic field.

Synchrotron XRD experiments under pressure using a DAC were separately carried out at room temperature in angledispersive mode with wavelength of $0.3738 \AA$ at the ID27 beam line ${ }^{21}$ at ESRF. Helium was used as the pressure medium. Diffraction images were recorded on a fast, large-area scanning MAR 165 CCD detector. The image data were integrated using the FIT2D software package, ${ }^{22}$ and the resulting diffraction patterns were analyzed with the Fullprof package program. ${ }^{23}$

The magnetic field dependence of magnetization in the pressure range up to $26 \mathrm{GPa}$ at room temperature was measured by using both a superconducting quantum interference device 
(SQUID) magnetometer and a miniature diamond anvil cell (mDAC) made of nonmagnetic hardened CuBe. This mDAC is shown in detail in Ref. 24. We have used diamond anvils with the culet size of $0.5 \mathrm{~mm}$ and a nonmagnetic $\mathrm{CuBe}$ or Re gasket with the thickness of $0.2 \mathrm{~mm}$. Furthermore, cobalt foils as a dummy material were located near the gasket (not on the gasket). As for the pressure-transmitting medium, we used Apiezon-J oil, and the ruby fluorescence technique has been used for pressure calibration.

\section{RESULTS AND DISCUSSION}

\section{A. Pressure dependence of XANES and XMCD spectra at the Fe K-edge}

Figure 2 shows the XANES and XMCD spectra of $\mathrm{Co}_{x} \mathrm{Fe}_{3-x} \mathrm{O}_{4}(x=0,1,1.5$, and 2) samples at the Fe K-edge at room temperature and ambient pressure. These spectra are similar to previously reported ones. ${ }^{17,25-27}$ In spite of the difference in the Fe content, the energy line shape of the XANES spectra closely resembles each other in both pre-edge and main-edge regions, as shown in Fig. 2(a). In addition, there is no chemical shift among $\mathrm{CoFe}_{2} \mathrm{O}_{4}, \mathrm{Co}_{1.5} \mathrm{Fe}_{1.5} \mathrm{O}_{4}$, and $\mathrm{Co}_{2} \mathrm{FeO}_{4}$, but the threshold energy of the Co ferrites is shifted to higher energy than in the $\mathrm{Fe}_{3} \mathrm{O}_{4}$ spectrum by $\sim 1.8 \mathrm{eV}$. A chemical shift of about $4 \mathrm{eV}$ was observed between $\mathrm{Fe}^{2+}$ and $\mathrm{Fe}^{3+}$ water solutions, respectively. ${ }^{28}$ Thus, the XANES spectra indicate that $\mathrm{Fe}$ ions in all the cobalt ferrites exist as

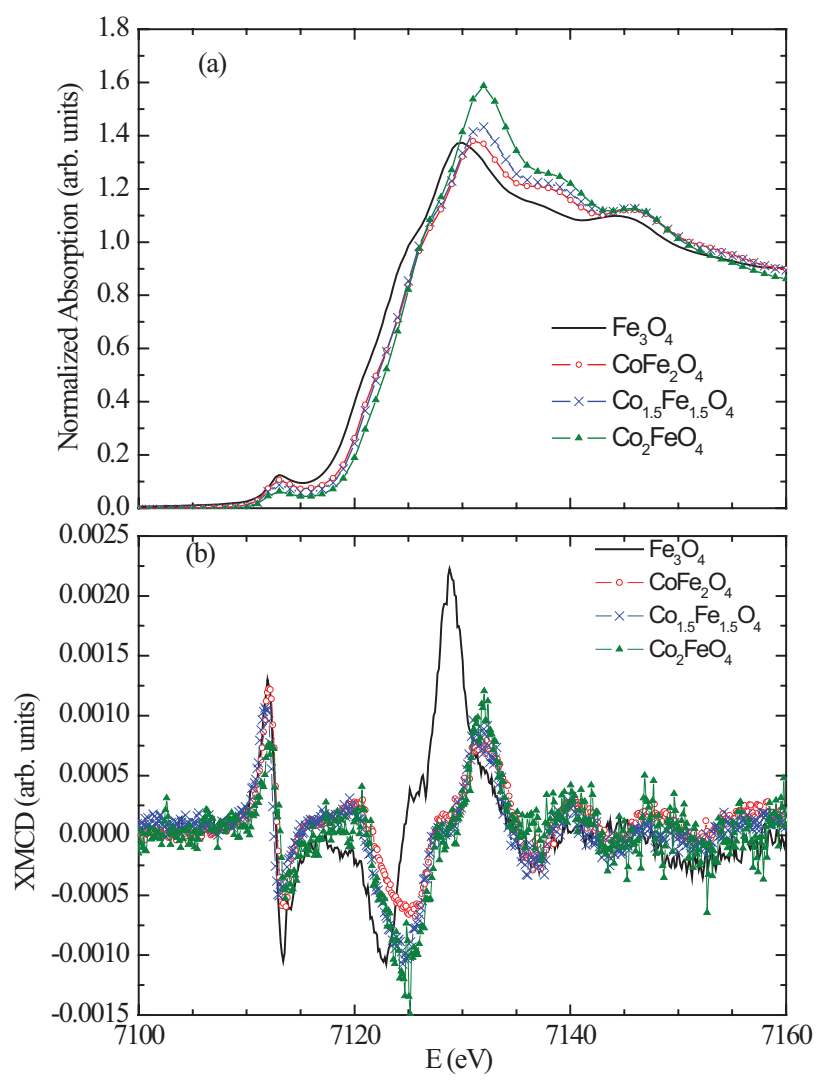

FIG. 2. (Color online) (a) The normalized XANES spectra of $\mathrm{Co}_{x} \mathrm{Fe}_{3-x} \mathrm{O}_{4}(x=0,1,1.5$, and 2$)$ samples collected at the Fe K-edge at room temperature and ambient pressure. (b) The corresponding normalized XMCD at the same P-T. trivalent ions, $\mathrm{Fe}^{3+}$ and should have a similar electronic state independently of the Co content.

Figure 2(b) shows the Fe K-edge XMCD spectra in this series. All the spectra show two dispersion-type XMCD signals at the pre-edge and the main-edge regions, respectively, showing opposite signs. XMCD experiments at the Fe K-edge for $\mathrm{Mn}$ and $\mathrm{Mn}-\mathrm{Zn}$ normal-spinel ferrites do not show the positive-to-negative dispersion-type signal in the pre-edge region, ${ }^{26,27}$ which indicates that the prepeak signal mainly originates from $\mathrm{Fe}^{3+}$ atoms in the tetrahedral A sites. Starting from $\mathrm{CoFe}_{2} \mathrm{O}_{4}$ and increasing the Co content, the amplitude of the XMCD signal at the pre-edge decreases in agreement with the decrease of the occupancy of $\mathrm{Fe}^{3+}$ in the A sites (Fig. 1). On the other hand, a negative-to-positive dispersion-type signal is observed in the main-edge region. Such XMCD signals are shifted to higher energies in the Co ferrites, in agreement with the chemical shift observed in the XANES spectra [Fig. 2(a)], as only $\mathrm{Fe}^{3+}$ ions are present in these ferrites. Its amplitude is also rather reduced with respect to $\mathrm{Fe}_{3} \mathrm{O}_{4}$. However, it is not clear whether this negative-to-positive dispersion-type signal in the main-edge region can be associated with $\mathrm{Fe}$ atoms in the octahedral B sites only ${ }^{17,25-27}$ or whether all $\mathrm{Fe}$ atoms contribute (in tetrahedral and octahedral sites). ${ }^{11,13}$

There is a general agreement that the XMCD signals at the K-edges of $3 \mathrm{~d}$ transition metals derives from the spin-orbit coupling in the empty $4 \mathrm{p}$ bands, ${ }^{29,30}$ the magnetism of which is mainly induced by the orbital moment of the $3 \mathrm{~d}$ states through the $4 \mathrm{p}-3 \mathrm{~d}$ hybridization. This means that the different nature of hybridization in the tetrahedral (no inversion symmetry) and octahedral (with inversion symmetry) cases coming from the different symmetry of these sites could result in XMCD signals of different sign and intensity appearing at different positions in energy. As mentioned previously, only tetrahedral Fe sites contribute to the first dispersion-type signal in the XMCD spectra so its variation in amplitude would reflect that of the magnetization of the tetrahedral Fe sublattice, while contributions to the second dispersion-type signal remain controversial so far. Therefore, we study the pressure variation of the total amplitude of the XMCD signals as a measure of the global magnetization of the Fe sublattice. This assumption is justified because both XMCD signals at the pre-edge and main-edge regions separately show the same pressure variation, as we discuss below.

Figure 3 compares the normalized Fe K-edge XANES (upper panel) and XMCD (lower panel) data of $\mathrm{Fe}_{3} \mathrm{O}_{4}$ from $3.4 \mathrm{GPa}$ to $24.5 \mathrm{GPa}$ during a pressure increase ramp. The XANES spectra do not show any appreciable structural or electronic change under pressure except for the monotonic energy shift to higher energies of the oscillations in the extended region due to the compression effect, in agreement with previous works. ${ }^{11-13}$ However, the XMCD spectra show a continuous decrease of the peak-peak amplitude of the two dispersion-type signals at around 7112-7113 eV and $7123-7129 \mathrm{eV}$, respectively. They are labeled in Fig. 3 as $\mathrm{A}-\mathrm{A}^{\prime}$ and $\mathrm{B}-\mathrm{B}^{\prime}$, respectively. This peak-peak amplitude is proportional to the absolute value integral, so to quantify the reduction of the amplitude of the XMCD signals, we use the absolute value integrals of the background subtracted data in the energy ranges 7110-7115 eV and 7120-7135 eV for the $\mathrm{A}-\mathrm{A}^{\prime}$ and $\mathrm{B}-\mathrm{B}^{\prime}$ peaks, respectively. In the following, we 

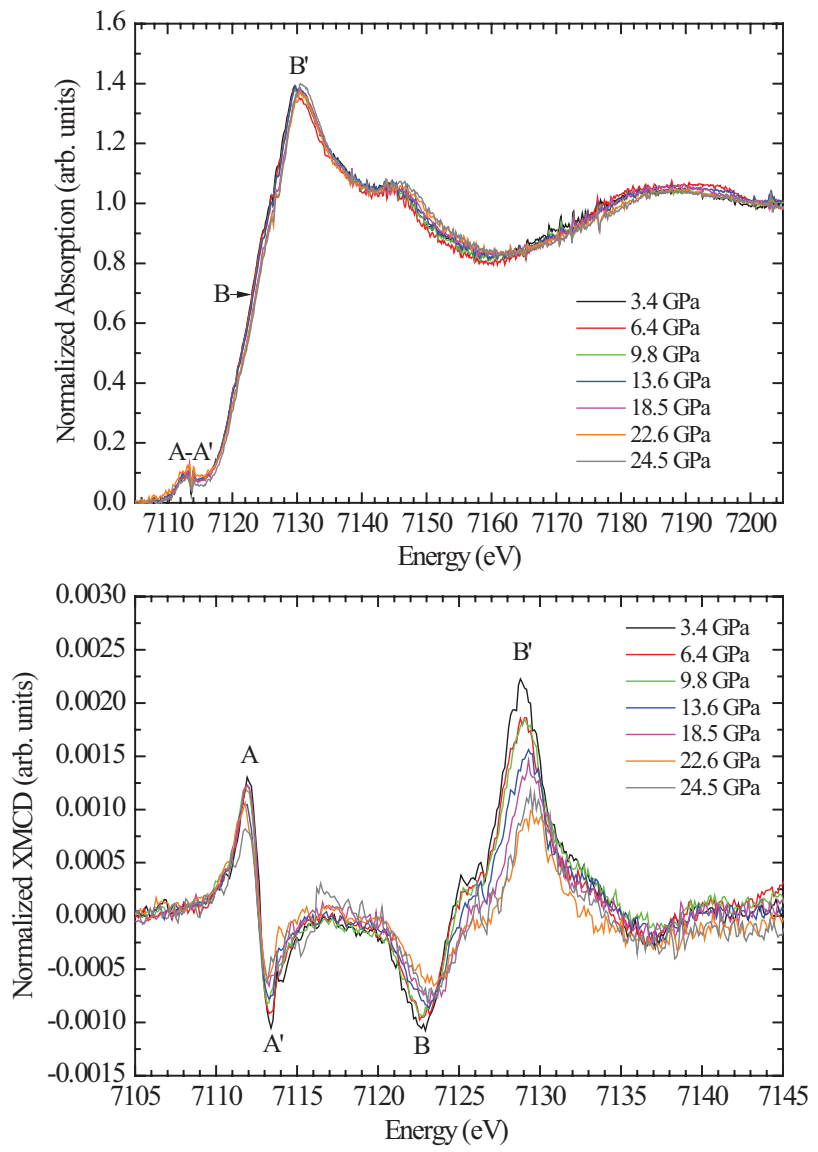

FIG. 3. (Color online) XANES (upper panel) and XMCD (lower panel) spectra at the $\mathrm{Fe} \mathrm{K}$-edge of $\mathrm{Fe}_{3} \mathrm{O}_{4}$ as a function of pressure from 3.4 GPa to $24.5 \mathrm{GPa}$.

call "amplitude" the absolute value integral for simplicity. In Fig. 4, we plot the evolution of the amplitudes of the two XMCD double peaks as a function of pressure. Below $P \sim$ $15 \mathrm{GPa}$, the amplitudes are almost constant, and then they start decreasing continuously, showing roughly equal $50 \%$ reduction at $25 \mathrm{GPa}$. This evolution is compatible with the data shown in Ref. 13 and agrees with the high-pressure structural and magnetic modification of magnetite. ${ }^{7,9}$ Upon pressure release, the XMCD signal recovers to its corresponding value at ambient pressure (Fig. 4). This indicates a continuous decrease of the global magnetization of $\mathrm{Fe}_{3} \mathrm{O}_{4}$ with increasing pressure even before the structural transformation occurs at $25 \mathrm{GPa}$.

The pressure dependence of the normalized Fe K-edge XMCD (left panel) and XANES (right panel) data of $\mathrm{CoFe}_{2} \mathrm{O}_{4}$, $\mathrm{Co}_{1.5} \mathrm{Fe}_{1.5} \mathrm{O}_{4}$, and $\mathrm{Co}_{2} \mathrm{FeO}_{4}$ are shown in Figures 5, 6, and 7, respectively. For $\mathrm{CoFe}_{2} \mathrm{O}_{4}$, as seen in Fig. 5, the Fe K-edge $\mathrm{XMCD}$ spectrum shows no remarkable variation in the range of pressure from ambient pressure to $23 \mathrm{GPa}$. When the applied pressure is increased above this pressure, the XMCD amplitude strongly diminishes, and it is almost disappeared at $27 \mathrm{GPa}$. The XANES data show clearly that the local structure around $\mathrm{Fe}$ is also modified above $23 \mathrm{GPa}$ : the prepeak at $7113 \mathrm{eV}$ becomes less intense and the features at the main-edge region of energies become less resolved. Therefore, the magnetic transition is accompanied by a structural transition. On the

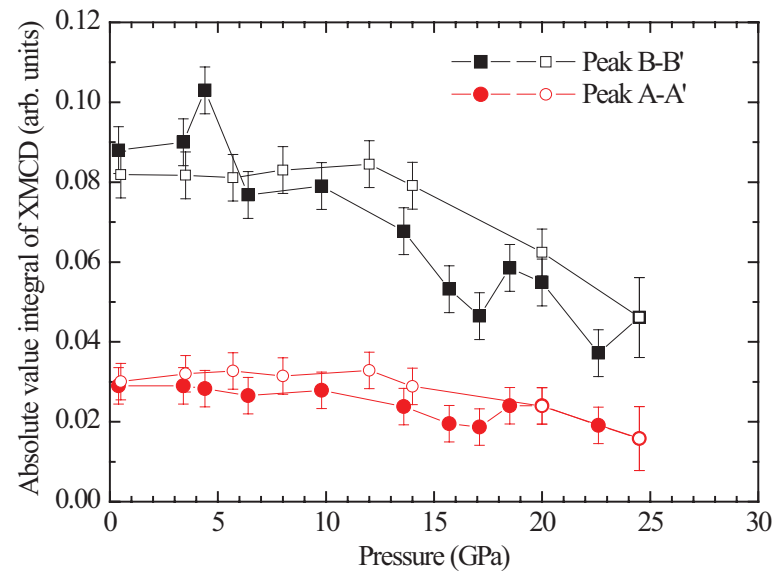

FIG. 4. (Color online) The evolution of the absolute value integral of the XMCD peaks A-A' (red circles) and B-B' (black squares) at the $\mathrm{Fe} \mathrm{K}$-edge of $\mathrm{Fe}_{3} \mathrm{O}_{4}$ during a cycle of compression (closed symbols) and decompression (open symbols). Error bars indicate the standard deviation, and the line is a guide for the eyes.

other hand, during the decompression process, both the $\mathrm{Fe}$ K-edge XMCD and the XANES spectra do not recover down to $3 \mathrm{GPa}$. In contrast, as seen in Figs. 6 and 7, the Fe K-edge XMCD spectrum of $\mathrm{Co}_{1.5} \mathrm{Fe}_{1.5} \mathrm{O}_{4}$ and $\mathrm{Co}_{2} \mathrm{FeO}_{4}$, respectively, shows a continuous decrease of its overall amplitude with increasing pressure, and the simultaneous-obtained XANES spectra show poor variation. When the pressure is released, the XMCD spectra recover intensity.

The pressure dependence of the total absolute integral of the background subtracted XMCD signals correspondent to the energy ranges 7110-7115 eV plus 7121-7135 eV for $\mathrm{CoFe}_{2} \mathrm{O}_{4}, \mathrm{Co}_{1.5} \mathrm{Fe}_{1.5} \mathrm{O}_{4}$, and $\mathrm{Co}_{2} \mathrm{FeO}_{4}$ are compared in Fig. 8 . For $\mathrm{CoFe}_{2} \mathrm{O}_{4}$, this amplitude shows a constant value within the error up to $24 \mathrm{GPa}$ followed by a drastic drop at $27 \mathrm{GPa}$ of about $80 \%$ of its value at ambient pressure. A broad pressure hysteresis in this magnetic transition is demonstrated
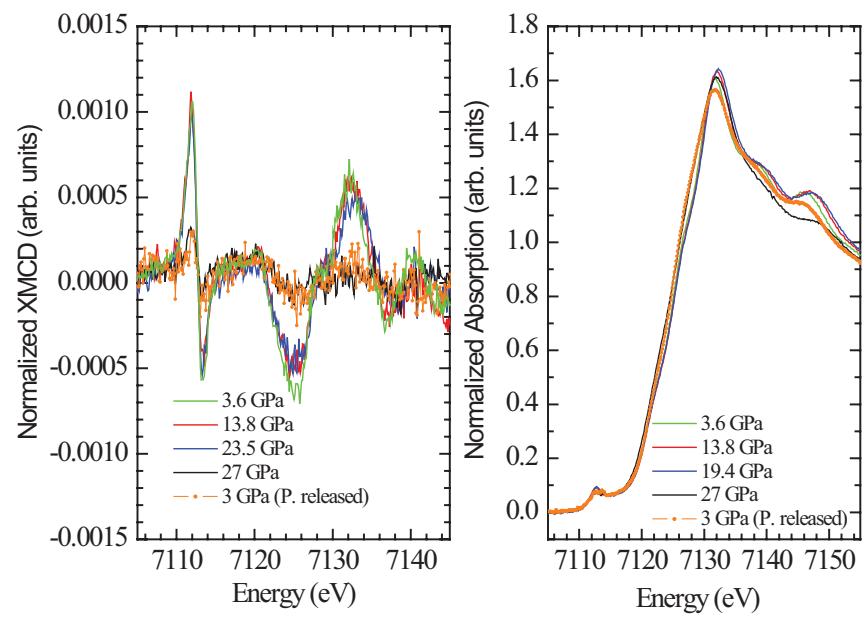

FIG. 5. (Color online) Pressure variation of Fe K-edge XMCD spectra (left panel) and some examples of XANES spectra (right panel) of $\mathrm{CoFe}_{2} \mathrm{O}_{4}$. Solid lines indicate data for increasing pressure, and the spectrum after the decompressing process is marked by line + dots. 

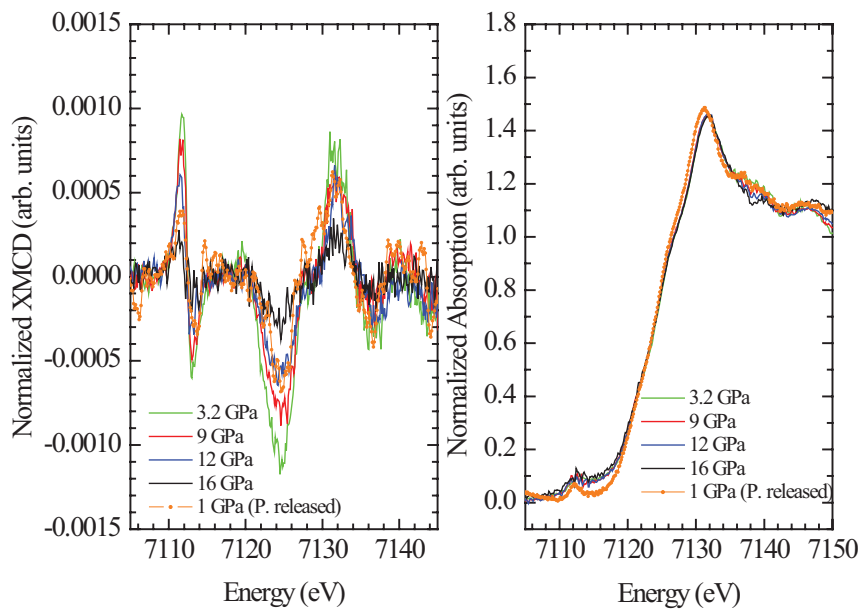

FIG. 6. (Color online) Pressure variation of Fe K-edge XMCD (left panel) and some examples of XANES (right panel) spectra of $\mathrm{Co}_{1.5} \mathrm{Fe}_{1.5} \mathrm{O}_{4}$. Solid lines indicate data for increasing pressure, and the spectrum after the decompressing process is marked by line + dots.

by compression and decompression processes. In this case, the amplitude of XMCD is stabilized with a low intensity almost to the final state at ambient pressure, so the complete suppression of the Fe-sublattice global magnetization is not reached. Moreover, the onset of the XMCD signal decay is observed in correspondence to changes in the XANES spectra, suggesting that a structural transition plays a driving role in the magnetic one. In contrast, a continuous linear decrease of the XMCD amplitude up to the maximum pressure measured is observed for $\mathrm{Co}_{1.5} \mathrm{Fe}_{1.5} \mathrm{O}_{4}$ and $\mathrm{Co}_{2} \mathrm{FeO}_{4}$ without any remarkable hysteresis in the increasing and decreasing pressure data. It is reduced by $70 \%$ of the value at ambient pressure for $\mathrm{Co}_{1.5} \mathrm{Fe}_{1.5} \mathrm{O}_{4}$ at $16 \mathrm{GPa}$ and for $\mathrm{Co}_{2} \mathrm{FeO}_{4}$ at $21 \mathrm{GPa}$. Consequently, it is expected that it will vanish for these two samples at sufficiently high pressure. The
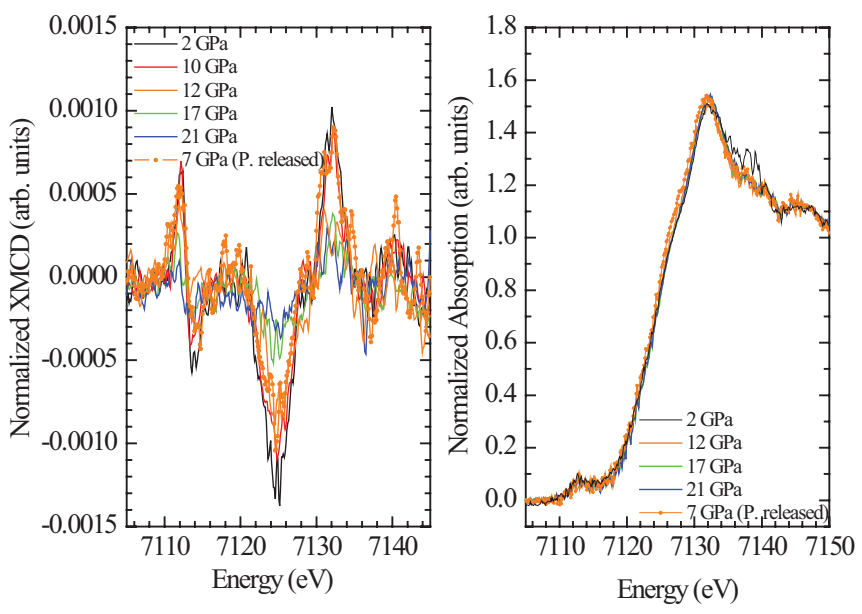

FIG. 7. (Color online) Pressure variation of Fe K-edge XMCD (left panel) and some examples of XANES (right panel) spectra of $\mathrm{Co}_{2} \mathrm{FeO}_{4}$. Solid lines indicate data for increasing pressure, and the spectrum after the decompressing process is marked by line + dots.

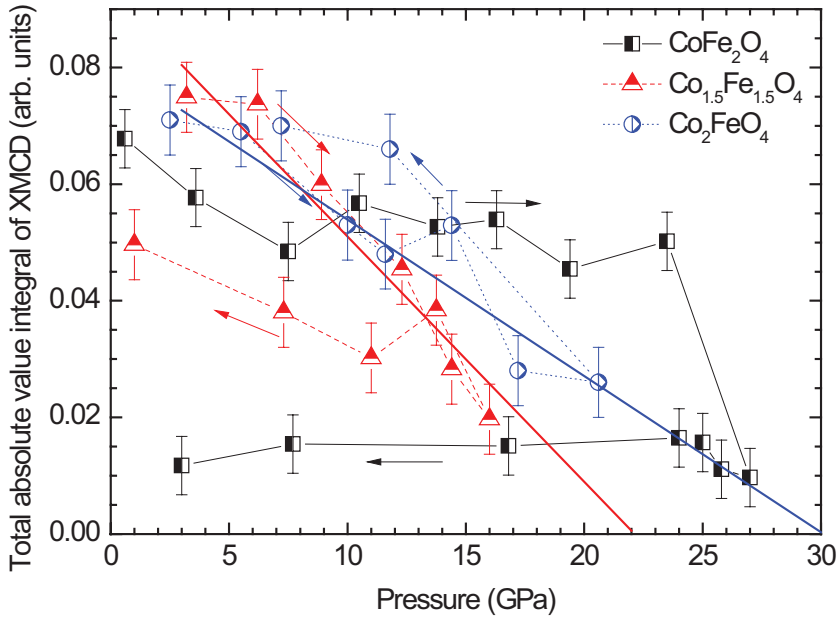

FIG. 8. (Color online) Pressure dependence of the total absolute value integral of the XMCD signal for $\mathrm{Co}_{x} \mathrm{Fe}_{3-x} \mathrm{O}_{4}(x=1,1.5$, and 2) samples at the Fe K-edge during a cycle of compression (closed symbols) and decompression (open symbols). Error bars indicate the standard deviation. The red and blue solid lines represent a linear fit of the XMCD data increasing pressure for $\mathrm{Co}_{1.5} \mathrm{Fe}_{1.5} \mathrm{O}_{4}$ and $\mathrm{Co}_{2} \mathrm{FeO}_{4}$, respectively.

extrapolation of a linear fit of the XMCD data to higher pressures predicts that $\mathrm{Fe}$-sublattice global magnetization will be lost at about $22 \mathrm{GPa}$ and $29 \mathrm{GPa}$ for $\mathrm{Co}_{1.5} \mathrm{Fe}_{1.5} \mathrm{O}_{4}$ and $\mathrm{Co}_{2} \mathrm{FeO}_{4}$, respectively, as shown in Fig. 8. When the pressure is released, the value of the XMCD amplitude for $\mathrm{Co}_{1.5} \mathrm{Fe}_{1.5} \mathrm{O}_{4}$ at ambient pressure is lower than the initial state one, whereas the transition is regarded as completely reversible in $\mathrm{Co}_{2} \mathrm{FeO}_{4}$. These results reveal major differences in the pressure evolution of $\mathrm{Fe}$-sublattice global magnetization of $\mathrm{CoFe}_{2} \mathrm{O}_{4}$ with respect to $\mathrm{Co}_{1.5} \mathrm{Fe}_{1.5} \mathrm{O}_{4}$ and $\mathrm{Co}_{2} \mathrm{FeO}_{4}$. In the former, this global magnetization is almost not affected by compression until its drastic decrease at the structural transformation, similarly to pure $\mathrm{Fe}$ (Ref. 31) and $\mathrm{FeCo}$ alloys. ${ }^{32}$ In the latter ones, compression has an immediate effect on this global magnetization, causing a continuous strong linear decay and resembling more the behavior of pure Co (Ref. 33).

We now discuss the different behavior of the loss of the $\mathrm{Fe}$-sublattice global magnetization with pressure based on the structural differences at ambient pressure. In the $\mathrm{CoFe}_{2} \mathrm{O}_{4}$ inverse spinel, the magnetization of the A-site and $\mathrm{B}$-site Fe-sublattices align collinear antiparallel because the $\mathrm{AB}$ antiferromagnetic exchange interaction $\left(J_{\mathrm{AB}}\right)$ is the predominant magnetic interaction. Creating an imbalance between sublattice magnetizations, as for example, substituting $\mathrm{Co}^{2+}$ for A-site $\mathrm{Fe}^{3+}$ cations in the Co-rich $(x>1)$ ferrites (Fig. 1), the strength of $J_{\mathrm{AB}}$ is reduced and then a canting of the A-site and/or B-site magnetizations can occur, resulting in a more unstable ferrimagnetism when applying pressure. This fact could explain the different pressure evolution shown by the $\mathrm{Fe}$ XMCD signal between $\mathrm{CoFe}_{2} \mathrm{O}_{4}$ and $\mathrm{Co}_{1+x} \mathrm{Fe}_{2-x} \mathrm{O}_{4}(x=0.5$ and 1) ferrites, which are partially inverse spinels. Moreover, the fully disordered $\mathrm{Co}_{1.5} \mathrm{Fe}_{1.5} \mathrm{O}_{4}$ spinel $(i=0.7)$ shows the loss of the Fe-sublattice magnetization at the lowest pressure. 

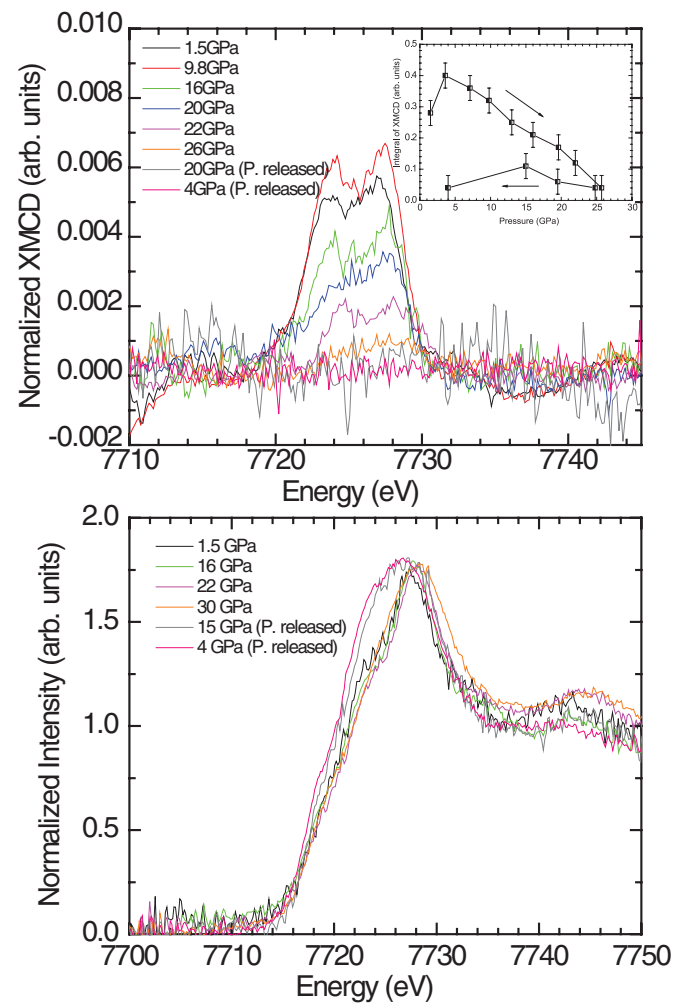

FIG. 9. (Color online) Pressure variation of Co K-edge XMCD spectra (upper panel) and some examples of XANES (lower panel) spectra of $\mathrm{CoFe}_{2} \mathrm{O}_{4}$. The inset shows the pressure dependence of the integral of the XMCD peak. Error bars indicate the standard deviation, and the line is a guide for the eyes.

\section{B. Pressure dependence of XANES and XMCD spectra at the $\mathrm{Co} \mathrm{K}$-edge of $\mathrm{CoFe}_{2} \mathrm{O}_{4}$}

To fully characterize the high-pressure magnetic state in this sample, we have separately carried out pressure-dependent XMCD experiments at the Co K-edge. Figure 9 shows the combined XMCD and XANES data at the Co K-edge of $\mathrm{CoFe}_{2} \mathrm{O}_{4}$ as a function of pressure. In XANES, the spectra exhibit an enhanced white-line-like absorption and no prepeak intensity. In XMCD, a positive signal with a double peak appears at about $7726 \mathrm{eV}$ that corresponds to the white line of XANES spectra but no dichroic signal at the prepeak is observed. These experimental facts demonstrate that $\mathrm{Co}^{2+}$ is preferably substituted for the $\mathrm{Fe}^{2+}$ in octahedral sites. The XMCD spectral profile coincides with those previously reported by Kita et al. ${ }^{17}$ and Kawamura et al. ${ }^{34}$ and can be explained as arising from the $\mathrm{Co}^{2+}$ ions in the $\mathrm{B}$ sites of $\mathrm{CoFe}_{2} \mathrm{O}_{4}$ that should be in the high-spin state. As the pressure increases, the double-peaked XMCD signal continuously decreases down to $20 \%$ of its value at room pressure at the pressure $P_{c} \sim 26 \mathrm{GPa}$, in contrast to the drastic decay observed at the $\mathrm{Fe} \mathrm{K}$-edge. However, the XMCD signal suppression occurs at the same pressure for both $\mathrm{Fe}$ and $\mathrm{Co} \mathrm{K}$-edge. Under decompression, the Co K-edge XMCD signal is not restored either (see inset of Fig. 9 upper panel), which confirms that the magnetic transition in $\mathrm{CoFe}_{2} \mathrm{O}_{4}$ is therefore irreversible. In the critical region of pressures, simultaneously with the magnetic transition, a change is also observed in the XANES spectra at

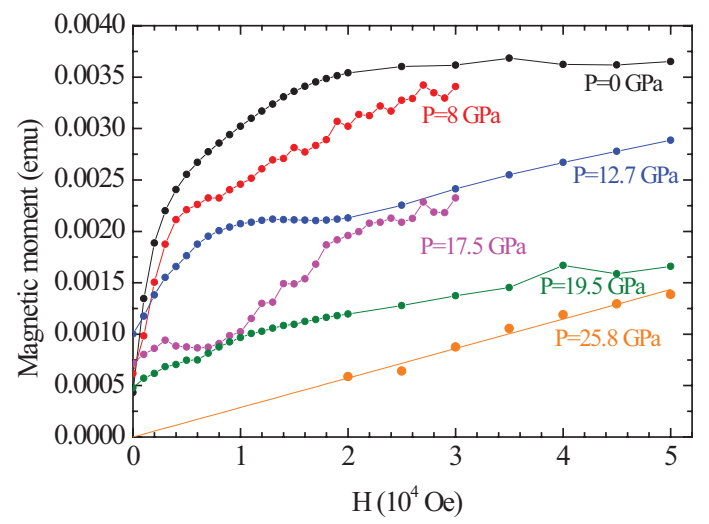

FIG. 10. (Color online) Magnetization curves of $\mathrm{CoFe}_{2} \mathrm{O}_{4}$ vs the external magnetic field for selected pressures between ambient pressure and $26 \mathrm{GPa}$.

the Co K-edge, as shown in Fig. 9 lower panel. This is a sign of a change in the electronic structure of the Co atoms in the high-pressure phase.

\section{Pressure dependence of bulk magnetization in $\mathrm{CoFe}_{2} \mathrm{O}_{4}$}

The straightforward conclusion from the previous XMCD measurements is the pressure-induced disappearance of $\mathrm{Fe}$ and Co-sublattice magnetizations in $\mathrm{CoFe}_{2} \mathrm{O}_{4}$. However, $\mathrm{XMCD}$ alone cannot disentangle a transition to a paramagnetic state (loss of the magnetic order) from the disappearance of the local magnetic moments (magnetic collapse). In order to determine the exact nature of the high-pressure magnetic state, we should compare with the pressure dependence of the bulk magnetization. We recall here that in $\mathrm{CoFe}_{2} \mathrm{O}_{4}$, Co has the largest contribution in the formation of the total magnetic moment because of antiparallel alignment of $\mathrm{Fe}^{3+}$ at tetrahedral and octahedral sites. However, a small contribution of $\mathrm{Fe}$ is still deduced from magnetic Compton scattering. ${ }^{35}$ This fact is reflected in the amplitude of the XMCD signals at the Fe (Fig. 5) and Co (Fig. 9) K-edges, which is about five times larger for the Co K-edge. Magnetometric measurements under high pressure are difficult because of the weakness of the magnetic signal coming from the sample, and four runs of measurements were carried out at room temperature to obtain comprehensive results. In Fig. 10, the magnetic field dependence of the bulk magnetic moment $(M)$ is given for several pressures from $P=0 \mathrm{GPa}$ up to $P=26 \mathrm{GPa}$ at $293 \mathrm{~K}$. It is clear that the magnetization up to $P=8 \mathrm{GPa}$ shows the typical feature of a ferromagnet, as expected from the major contribution of the Co-sublattice ferromagnetism to the bulk magnetization, and appears to saturate at around $2 \mathrm{kOe}$. For higher pressures up to $19 \mathrm{GPa}$, the magnetization still resembles the ferromagnetic behavior, but it does not reach saturation even at the highest field of $5 \mathrm{kOe}$. At $P=26 \mathrm{GPa}$, the magnetization is nearly proportional to the magnetic field without saturation and approaches zero at $H=0 \mathrm{Oe}$, suggesting that high-pressure $\mathrm{CoFe}_{2} \mathrm{O}_{4}$ is either paramagnetic or antiferromagnetic. The pressure dependence of the magnetic moment obtained from the SQUID measurements at two values of the magnetic field, $H=10 \mathrm{kOe}$ and $50 \mathrm{kOe}$, is summarized in Fig. 11, where all the data points are plotted 


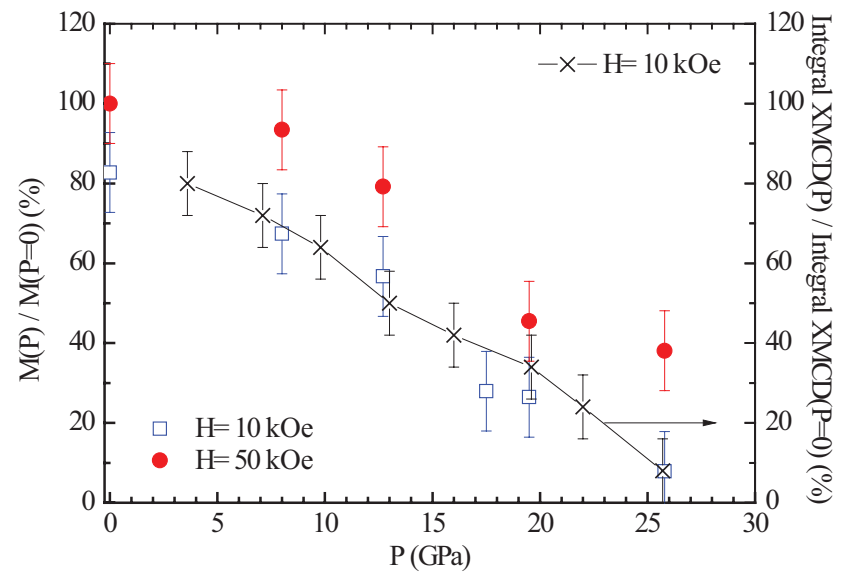

FIG. 11. (Color online) Pressure dependence of the magnetization of $\mathrm{CoFe}_{2} \mathrm{O}_{4}$ observed at the external magnetic fields $H=10 \mathrm{kOe}$ (open squares) and $H=50 \mathrm{kOe}$ (full circles), which is compared to the pressure variation of the Co K-edge XMCD integrated intensity.

with normalization against the saturation value at ambient pressure. The pressure dependence of the integral of the XMCD signal at the Co K-edge at $H=10 \mathrm{kOe}$ is also shown in Fig. 11 for comparison. The bulk magnetic moment obtained from the SQUID measurements yield similar pressure dependence to the integral of the Co K-edge XMCD intensity, which confirms the major contribution of Co ferromagnetism to the bulk magnetization. As pressure increases, the bulk magnetization continuously decreases, and the intensity of $M(H=10 \mathrm{kOe})$ at $P=26 \mathrm{GPa}$ was suppressed down to about $10 \%$ of the initial one. However, $M(H=50 \mathrm{kOe})$ at $P=26 \mathrm{GPa}$ was only suppressed down to about $40 \%$ of its initial value. This marked change in the slope of $M(P)$ vs $H$ indicates that measurable magnetization is easily induced by an external magnetic field and saturation should be reached at high pressure applying a sufficiently high magnetic field. The present results of the bulk magnetization point to a transition into a paramagnetic state or a collinear antiferromagnetic state as the most likely mechanism to explain the pressure-induced disappearance of the ferrimagnetic ordering in $\mathrm{CoFe}_{2} \mathrm{O}_{4}$ as derived from the XMCD study. We recall that the magnetic collapse will induce a Pauli paramagnetic high-pressure state. Thus, we have estimated the DC magnetic susceptibility of $\mathrm{CoFe}_{2} \mathrm{O}_{4}$ at $300 \mathrm{~K}$ and $26 \mathrm{GPa}$ to be about $6.5 \times 10^{-5} \mathrm{emu} / \mathrm{g}$. This value is one or two orders of magnitude larger than typical Pauli magnetic susceptibilities, ${ }^{36}$ which suggests that $\mathrm{CoFe}_{2} \mathrm{O}_{4}$ at high-pressure corresponds well with a paramagnet of localized moments.

\section{High-pressure phase transformations of $\mathrm{Co}_{x} \mathrm{Fe}_{3-x} \mathrm{O}_{4}(x=1$, 1.5, and 2): Correlation between the crystal and magnetic state}

The x-ray absorption spectra of $\mathrm{CoFe}_{2} \mathrm{O}_{4}$ at both $\mathrm{Fe}$ and Co K-edges indicate a structural transition in the pressure range between 24 and $27 \mathrm{GPa}$, simultaneous with the magnetic one. In order to determine the high-pressure polymorphs of the $\mathrm{Co}_{x} \mathrm{Fe}_{3-x} \mathrm{O}_{4}(x=1,1.5$, and 2), spinel compounds, and the relationship with their high-pressure magnetic state, we have carried out $\mathrm{x}$-ray powder diffraction measurements up to

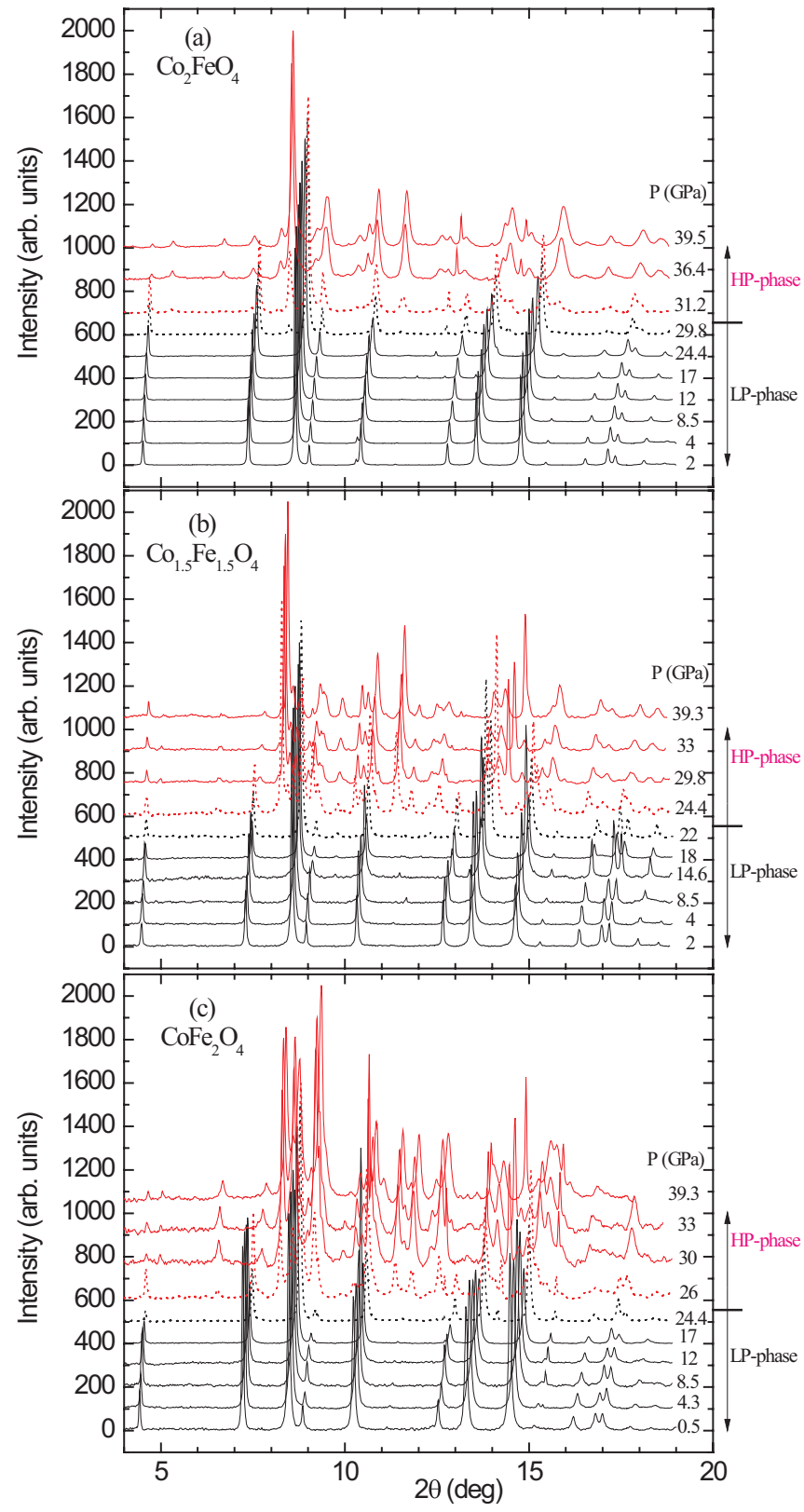

FIG. 12. (Color online) X-ray diffraction of $\mathrm{Co}_{2} \mathrm{FeO}_{4}$ (a), $\mathrm{Co}_{1.5} \mathrm{Fe}_{1.5} \mathrm{O}_{4}$ (b), and $\mathrm{CoFe}_{2} \mathrm{O}_{4}$ (c) obtained during the compression run. The downward $(\downarrow)$ and upward $(\uparrow)$ arrows indicate the disappearance of the cubic spinel phase (black lines) and the appearance of the new high pressure phase (red lines), respectively.

40 GPa. Figures 12(a)-12(c) show representative diffraction patterns measured for the three samples. The patterns can be indexed with the cubic spinel structure up to the critical pressures $\left(P_{c}\right)$ of $24 \mathrm{GPa}, 22 \mathrm{GPa}$, and $29 \mathrm{GPa}$ for $\mathrm{CoFe}_{2} \mathrm{O}_{4}$, $\mathrm{Co}_{1.5} \mathrm{Fe}_{1.5} \mathrm{O}_{4}$, and $\mathrm{Co}_{2} \mathrm{FeO}_{4}$, respectively. Changes in the diffraction patterns are found at $P_{c}$, where the three samples show new diffraction lines that are not explained by the spinel-type structure. This indicates the onset of a phase transformation to another high-pressure phase. It is important to mark that the obtained critical pressures for the structural transformation in $\mathrm{Co}_{1.5} \mathrm{Fe}_{1.5} \mathrm{O}_{4}$ and $\mathrm{Co}_{2} \mathrm{FeO}_{4}$ samples coincide with the extrapolated values (Fig. 8) for which the 


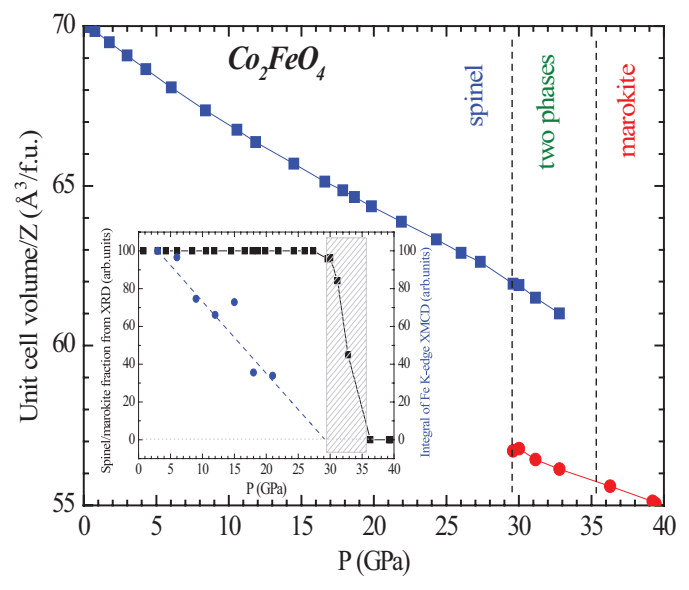

FIG. 13. (Color online) Variation of the unit cell volume of $\mathrm{Co}_{2} \mathrm{FeO}_{4}$ as a function of pressure. The vertical axis indicates $(\mathrm{V} / \mathrm{Z})$ for consistency in the volume change because of changes in $Z$ between low- and high-pressure phases. The inset compares the spinel/marokite phase fraction (black squares) from XRD and the integral of the Fe K-edge XMCD signal (blue circles) with pressure. In the dashed area, the spinel-marokite coexistence region is indicated by XRD.

pressure-induced extinction of the XMCD signals occur, i.e., the loss of the ferrimagnetic order.

Only the image for the $\mathrm{Co}_{2} \mathrm{FeO}_{4}$ sample shows smooth Debye-Scherrer rings, allowing for straightforward quantitative Rietveld refinement of the observed peak intensities. The best agreement between the observed and calculated patterns has been achieved when considering the orthorhombic $\mathrm{CaMn}_{2} \mathrm{O}_{4}$-type (marokite) structure. The results obtained for the evolution of the unit cell as a function of pressure are shown in Fig. 13. The transition from the cubic to the orthorhombic phases involves an estimated volume collapse of around $5 \%$ at the transition and a coexistence region from 29 to $36 \mathrm{GPa}$, i.e., it is a first-order transition. In the inset, we compare the pressure evolution of the integral of the main XMCD peak at the $\mathrm{Fe}$ K-edge with the pressure evolution of the spinel/marokite phase fraction as estimated from the Rietveld analysis. Compression immediately decrease the Fe K-edge XMCD signal, long before the onset of the structural transition, and this onset into a mixed spinel-marokite phase is expected to occur simultaneously with the total extinction of the XMCD signal. For the other two cobalt ferrites, the high-pressure XRD patterns are affected by preferred orientation and show the presence of more than one postspinel polymorph, probably those of the orthorhombic postspinel $\mathrm{CaMn}_{2} \mathrm{O}_{4}$-type (space group: $\mathrm{Pbcm}$ ) and $\mathrm{CaFe}_{2} \mathrm{O}_{4}$-type (space group: Pnma) structures. Further high-pressure studies are needed to clarify the structural properties of the high-pressure phases of $\mathrm{CoFe}_{2} \mathrm{O}_{4}$ and $\mathrm{Co}_{1.5} \mathrm{Fe}_{1.5} \mathrm{O}_{4}$. However, all these high-pressure postspinel structures are denser than the spinel one, which results in more distorted polyhedron around Fe and Co crystallographic sites.
This could modify the superexchange magnetic interaction and favor the disappearance of the ferromagnetic order.

From our XRD data we have deduced that the critical pressures for the structural transformation in $\mathrm{Co}_{1.5} \mathrm{Fe}_{1.5} \mathrm{O}_{4}$ and $\mathrm{Co}_{2} \mathrm{FeO}_{4}$ are higher than the maximum pressure achieved in the XMCD experiments. This means that these two samples were still in the cubic spinel phase, which can explain why their XMCD signals are found to be reversible upon decompression. On the other hand, the high-pressure phase of $\mathrm{CoFe}_{2} \mathrm{O}_{4}$ is quenchable upon release of pressure.

\section{CONCLUSIONS}

We have carried out XMCD and magnetization studies to pressures of $30 \mathrm{GPa}$ combined with XRD studies up to $40 \mathrm{GPa}$ to explore the pressure-induced phase transformations of $\mathrm{Co}_{x} \mathrm{Fe}_{3-x} \mathrm{O}_{4}$ ferrites. All samples are ferrimagnetic and crystallize with a cubic spinel structure at ambient pressure. Upon increase of pressure, XRD and Fe K-edge XMCD measurements indicate that $\mathrm{CoFe}_{2} \mathrm{O}_{4}$ is almost unaffected by compression until $\sim 27 \mathrm{GPa}$, where it transforms to an orthorhombic structure, and Fe-sublattice magnetization (mainly arising from the antiferromagnetism between tetrahedral and octahedral sites) is strongly suppressed. Co K-edge XMCD measurements show that Co-sublattice magnetization (mainly ferromagnetic) is more sensitive to the effect of pressure, causing a linear decay from the initial applied pressure, but the magnetic transition occurs simultaneously at the two edges. This new high-pressure phase is metastable during decompression to ambient conditions. Bulk magnetization measurements, which reflects the major contribution of the $\mathrm{Co}$ ferromagnetism, show that the high-pressure magnetic phase in $\mathrm{CoFe}_{2} \mathrm{O}_{4}$ is actually either paramagnetic or collinear antiferromagnetic. $\mathrm{Co}_{1.5} \mathrm{Fe}_{1.5} \mathrm{O}_{4}$ and $\mathrm{Co}_{2} \mathrm{FeO}_{4}$ ferrites also transform into orthorhombic high-pressure structures at $\sim 24 \mathrm{GPa}$ and $\sim 30 \mathrm{GPa}$, respectively. The high-pressure phase of $\mathrm{Co}_{2} \mathrm{FeO}_{4}$ is consistent with the orthorhombic marokite structure. Differently from $\mathrm{CoFe}_{2} \mathrm{O}_{4}$, Fe K-edge XMCD measurements in the Co-rich samples indicate that compression causes an immediate decrease of Fe-sublattice magnetization without any structural modification. Indeed the collapse of the Fesublattice magnetization is expected to coincide with the onset of the respective structural phase transitions. Although we would expect a transition to either a paramagnetic or antiferromagnetic phase similar to $\mathrm{CoFe}_{2} \mathrm{O}_{4}$, we cannot completely rule out the total disappearance of the local magnetic moment in the mixed spinel/orthorhombic high-pressure phase of $\mathrm{Co}_{1.5} \mathrm{Fe}_{1.5} \mathrm{O}_{4}$ and $\mathrm{Co}_{2} \mathrm{FeO}_{4}$ ferrites.

\section{ACKNOWLEDGMENTS}

We thank ESRF for proving us with beam time. J. Jacobs is acknowledged for the preparation of the high pressure XRD DAC. This research was financed by the Spanish MICINN (Project No. MAT2012-38213-C02-01) and DGA (CAMRADS).
*Corresponding author: gloria@unizar.es

${ }^{1}$ I. S. Lyubutin and A. G. Gavriliuk, Phys. Usp. 52, 989 (2009).
${ }^{2}$ V. A. M. Brabers, in Hand Book of Magnetic Materials, edited by K. H. Buschow (North-Holland, Amsterdam, 1995), Vol. 8, p. 189. 
${ }^{3}$ J. García and G. Subías, J. Phys.: Condens. Matter 16, R145 (2004).

${ }^{4}$ H. K. Mao, T. Takahashi, W. Bassett, G. Kinsland, and L. Merrill,

J. Geophys. Res. 79, 1165 (1974)

${ }^{5}$ Y. Fei, D. J. Frost, H.-K. Mao, C. T. Prewitt, and D. Häusermann, Am. Mineral. 84, 203 (1999).

${ }^{6}$ C. Haavik, S. Stolen, H. Fjellvag, M. Hanfland, and D. Häusermann, Am. Mineral. 85, 514 (2000).

${ }^{7}$ L. S. Dubrovinsky, N. A. Dubrovinskaia, C. McCammon, G. Kh Rozenberg, R. Ahuja, J. M. Osorio-Guillen, V. Dmitriev, H.-P. Weber, T. Le Bihan, and B. Johansson, J. Phys.: Condens. Matter 15, 7697 (2003).

${ }^{8}$ M. P. Pasternak, S. Nasu, K. Wada, and S. Endo, Phys. Rev. B 50, 6446 (1994)

${ }^{9}$ W. M. Xu, G. Yu. Machavariani, G. Kh. Rozenberg, and M. P. Pasternak, Phys. Rev. B 70, 174106 (2004).

${ }^{10}$ E. R. Morris and Q. Williams, J. Geophys. Res. 102, 18139 (1997).

${ }^{11}$ Y. Ding, D. Haskel, S. G. Ovchinnikov, Y.-C. Tseng, Y. S. Orlov, J. C. Lang, and H. K. Mao, Phys. Rev. Lett. 100, 045508 (2008).

${ }^{12}$ G. Subías, V. Cuartero, J. García, J. Blasco, O. Mathon, and S. Pascarelli, J. Phys.: Conf. Ser. 190, 012089 (2009).

${ }^{13}$ F. Baudelet, S. Pascarelli, O. Mathon, J.-P. Itié, A. Polian and J.-C. Chervin, Phys. Rev. B 82, 140412(R) (2010).

${ }^{14}$ R. E. Cohen, I. I. Mazin, and D. G. Isaak, Science 275, 654 (1997).

${ }^{15}$ G. Subías, J. García, M. G. Proietti, J. Blasco, H. Renevier, J. L. Hodeau, and M. C. Sánchez, Phys. Rev. B 70, 155105 (2004).

${ }^{16}$ The cations distributions were obtained based on the decrease of the peak-height $\mathrm{A}-\mathrm{A}^{\prime}$ (Fig. 2) of the dispersion-type signal observed in the vicinity of the pre-edge peak of XANES spectra of $\mathrm{Co}_{x} \mathrm{Fe}_{3-x} \mathrm{O}_{4}\left(x=1.5\right.$ and 2) samples with respect to $\mathrm{CoFe}_{2} \mathrm{O}_{4}$, where the tetrahedral $\mathrm{A}$ sites are fully occupied by $\mathrm{Fe}^{3+}$. The remaining fraction of A sites is occupied by $\mathrm{Co}^{2+}$ that moves from the octahedral $\mathrm{B}$ sites when the substitution of $\mathrm{Co}^{3+}$ occurs to assure the charge balance.

${ }^{17}$ N. Kita, N. Shibuichi, and S. Sasaki, J. Synchrotron Radiat. 8, 446 (2001).

${ }^{18}$ P. J. Murray and J. W. Linnet, J. Phys. Chem. Solids 37, 619 (1975).
${ }^{19}$ J. Blasco, J. García, and G. Subías, Phys. Rev. B 83, 104105 (2011).

${ }^{20}$ S. Pascarelli, O. Mathon, M. Muñoz, T. Mairs, and J. Susini, J. Synchrotron Radiat. 13, 351 (2006).

${ }^{21}$ M. Mezouar, W. A. Crichton, S. Bauchau, H. Witsch, F. Torrecillas, G. Blattmann, P. Marion, Y. Dabin, J. Chavanne, O. Hignette, C. Morawe, and C. Borel, J. Synchrotron Radiat. 12, 659 (2005).

${ }^{22}$ A. P. Hammersley, S. O. Svensson, M. Hanfland, A. N. Fitch, and D. Häusermann, High Press. Res. 14, 235 (1996).

${ }^{23}$ J. Rodríguez-Carvajal, Physica B 192, 55 (1993). See also http://www.ill.eu/sites/fullprof/.

${ }^{24}$ M. Mito, M. Hitaka, T. Kawae, K. Takeda, T. Kitai, and N. Toyoshima, Jpn. J. Appl. Phys. 40, 6641 (2001).

${ }^{25}$ H. Maruyama, I. Harada, K. Kobayashi, and H. Yamazaki, Physica B 208-209, 760 (1995).

${ }^{26}$ N. Kawamura, H. Maruyama, K. Kobayashi, I. Inoue, and H. Yamazaki, J. Phys. IV (France) 7, C1 (1997).

${ }^{27}$ K. Matsumoto, F. Saito, T. Toyoda, K. Ohkubo, K. Yamawaki, T. Mori, K. Hirano, M. Tanaka, and S. Sasaki, Jpn. J. Appl. Phys. 39, 6089 (2000).

${ }^{28}$ J. García, G. Subías, V. Cuartero, and J. Herrero-Martín, J. Synchrotron Radiat. 17, 386 (2010).

${ }^{29}$ J. I. Igarashi and K. Hirai, Phys. Rev. B 50, 17820 (1994).

${ }^{30}$ G. Y. Guo, J. Phys.: Condens. Matter 8, L747 (1996).

${ }^{31}$ O. Mathon, F. Baudelet, J. P. Itié, A. Polian, M. d'Astuto, J. C. Chervin, and S. Pascarelli, Phys. Rev. Lett. 93, 255503 (2004).

${ }^{32}$ R. Torchio, S. Pascarelli, O. Mathon, C. Marini, S. Anzellini, P. Centomo, C. Meneghini, S. Mobilio, N. A. Morley, and M. R. J. Gibbs, High Press. Res. 31, 148 (2011).

${ }^{33}$ R. Torchio, A. Monza, F. Baudelet, S. Pascarelli, O. Mathon, E. Pugh, D. Antonangeli, and J. P. Itié, Phys. Rev. B 84, 060403(R) (2011).

${ }^{34}$ N. Kawamura, H. Maruyama, K. Kobayashi, S. Uemura, A. Urata, and H. Yamazaki, J. Phys. Soc. Jpn. 68, 923 (1999).

${ }^{35}$ H. S. Mund, S. Tiwari, J. Sahariya, M. Itou, Y. Sakurai, and B. L. Ahuja, J. Appl. Phys. 110, 073914 (2011).

${ }^{36}$ N. W. Ashcroft and N. D. Mermin, Solid State Physics (Cengage Learning Inc., Philadelphia, CA, 1976). 